\title{
Forty Years of Retinoblastoma; Into the Fifth Age
}

\author{
A C E McCARTNEY, ${ }^{1} \mathrm{~J}$ M OLVER, ${ }^{1,2} \mathrm{~J}$ E KINGSTON,${ }^{3}$ and J L HUNGERFORD, ${ }^{2,3}$ \\ London
}

\begin{abstract}
Summary
Forty years of research into retinoblastoma has seen wide-ranging changes in our knowledge of the histogenesis of this childhood tumour and in the treatment of the disease. These changes, and some of the more recent developments in the molecular biology of this tumour are reviewed.
\end{abstract}

Nineteen forty eight, the year the Institute opened, saw the development by Hyla B Stallard and George Innes, ${ }^{1,2,3}$ of the radioactive cobalt scleral plaque, a technique which revolutionised treatment and allowed vision to be preserved in patients with retinoblastoma. Since that time, the Department of Pathology has examined 1305 specimens of retinoblastoma, from all over the world. Much beside the treatment has altered in this period and many of the contemporary concepts about the disease at that time have become historical footnotes. Although research into the conventional histopathology of the disease continues at the Institute, the field has been widened with collaborative studies to include much more emphasis on genetics and molecular biology, as well as investigation of therapies. The mortality rate for retinoblastoma has dropped, from almost $100 \%$ (still true in some more deprived countries, where expert ophthalmological and genetic services are lacking) ${ }^{4}$ in the early 19th century, falling to $95 \%$ in 1867 and $43 \%$ in $1916 .{ }^{5}$ By 1948 it was recognised that survival was influenced by site, size, multiplicity, bilaterality and extension of the tumour along the optic nerve, falling dramatically if there was involvement of the cut end of the nerve, orbital extension or metastatic disease.
In countries with good ophthalmic, oncological and radiotherapeutic services, survival is assured for $92 \%$ of children with this disease but some children still die with intracranial extension, meningeal disease and haematogeneous spread. ${ }^{6}$ The last eight percent ${ }^{4}$ represents a challenge both in terms of diagnosis, and treatment; it includes patients, the nature of whose disease would not have been recognised in 1948. The most challenging group of patients to treat are those with ectopic intracranial retinoblastoma, 'trilateral retinoblastoma'. ${ }^{7,8,9,10}$ These patients are children, usually with bilateral retinoblastoma, who develop pineal or suprasellar tumours, in the "third eye' ${ }^{7}$ often some time after the initial presentation. ${ }^{8}$ In the past, these intracranial tumours would have been regarded as manifestations of metastatic rather than protean disease. CT scanning and MRI imaging have facilitated discovery of these tumours. Unfortunately, thus far, none of these patients have survived despite chemotherapy, ${ }^{11}$ and radiotherapy. Conventional histopathology of the globe has nothing to offer in terms of predicting which patients will develop ectopic intracranial retinoblastoma, but may influence the way some bilaterally or unilaterally affected children are treated.

From 'Department of Pathology, Institute of Ophthalmology, 17-25 Cayton Street, London, EC1. ${ }^{2}$ Moorfields Eye Hospital, City Road, London, EC1. ${ }^{3}$ Department of Oncology, St. Bartholomew's Hospital, London, EC1.

Correspondence to: Dr A C E McCartney, Department of Pathology, Institute of Ophthalmology, 17/25 Cayton Street, London, EC1 


\section{Histogenesis}

James Wardrop, ${ }^{12}$ the Edinburgh ophthalmologist, pioneered early removal of affected globes, and although his own patien.s did not survive because of infiltration of the optic nerve, his work on the clinical and pathological features of this tumour helped to establish the diagnosis. $\mathrm{He}$ called the tumour, fungus haematodes, echoing the initial description by Bartholinus (1667) of Pawin's patient, who had cranio-orbital extension of a tumour that was like 'brain mixed with dark blood and stone'. The histogensis, (derivation) of th:s tumour from the neural retina was clearly defined by Verhoeff in 1926, following the descriptions of tumour rosettes by Flexner (1881) and Wintersteiner (1897). ${ }^{5}$

Before the discovery of the ophthalmoscope, 19th century Moorfields ophthalmologists had 'muddied the waters' considerably. Travers (1824) attempted to differentiate between endophthalmitis and retinoblastoma, by incising the globe from one canthus to the other, remarking that if discoloured fluid escapes and the globe collapses this is not malignant disease and the cure is complete!' He also believed that the tumour could arise from any part of the globe except the cornea and lens, whilst his successor Turnbull (1849) believed it was only derived from the cornea. ${ }^{13}$ Neither used a microscope. Virchow's assertion that the tumour arose from glial tissue held great sway until 1926 when Verhoeff correctly recognised the histogenesis ${ }^{14}$ but even in 1941, tumours were still being classified into neuroepitheliomas and retinoblastomas, on the absence or presence of rosettes. ${ }^{15}$ This division proved somewhat arbitrary since tumours apparently without rosettes may be necrotic, and tumours often have a variable distribution of rosettes, being well developed in one area and scarce or poorly formed in another. The classification also supported the incorrect assumption that these tumours were glial in origin, rather than of neuroblastic origin, ${ }^{16}$ (probably specific to the retinal and pineal region) and that rosette formation is an attempt at photoreceptor differeniation. ${ }^{17}$ The electron microscopy of rosettes, including $9+0$ cilial elements and subsequently the discovery of even more differentiated and less radiosensitive ${ }^{18}$ photoreceptor-like structures, fleurettes, has allowed the classification to distinguish tumours consisting only of this type of structure. These latter tumours have been deemed benign and placed into a separate category called retinocytomas, a recently reintroduced and re-defined term. ${ }^{19,20}$

With the advent of monoclonal antibodies enabling histopathologists to identify cytological and cell surface markers consistently and with some ease, the great controversy of glial versus neuroblastic origin has re-emerged. Although retinoblastomas exhibit neurone-specific-enolase positivity, glial fibrillary acidic protein (GFAP) positivity has also been demonstrated. ${ }^{21,22}$ This latter positivity may be in reactive glial cells derived from non-tumourous retina rather than in the tumour cells themselves. In an electron microscopic study, an area of glial differention was shown, separate from the detached retina but also isolated from the undifferentiated retinoblastoma cells. ${ }^{23}$ Other workers ${ }^{21,24}$ have shown admixtures of both glial and photoreceptor cells in tumours whilst differentiation into neuroretinal endocrine cells of the amacrine type was shown by Sang and Albert. ${ }^{25}$

\section{Histopathological prognosis}

Current histopathological assessment of prognosis, in addition to the factors known of in 1948, takes into account the depth of invasion of the optic nerve, the amount of choroidal and scleral invasion, the presence or absence of intravascular tumour, the proportion of necrosis, the degree of photoreceptor differentiation and the possibility of a third site of origin.

In our recently completed series $^{26}$ on measurement of choroidal invasion in enucleated eyes from 80 children having choroidal invasion on initial histological presentation, multivariate analysis (MVA) untangled the interdependence of many of these variables. MVA showed only two independent predictors of survival, degree of optic nerve invasion and amount of choroidal invasion. Used in conjunction with survival curves, MVA showed that major choroidal invasion $\gg 3 \mathrm{~mm}^{2}$ and post-laminal invasion, (as well as invasion to the cut end) had an additive effect. This diminished survival in these patients was probably due to increased shedding of tumour cells into the choroidal blood stream, as seven of the 10 children with major choroidal invasion and post-laminal optic nerve disease, died of metastases (only four of the seven had 
tumours extending to the cut end of the nerve). Degree of differentiation and extrascleral invasion were predictive of clinical outcome by univariate analysis but not on multivariate.

Taktikos $^{27}$ in 1966 reviewed 287 enucleated eyes from cases of retinoblastoma at the Institute and showed that most cases are diagnosed at between one and four years of age. He commented that diagnosis after seven years is very rare. A recent case history ${ }^{28}$ documented a unilateral sporadic tumour in a seven year old child with an apparently unique distribution. There were only two tiny foci of retinal disease but a massive involvement of the iris and ciliary body. A more common diffuse form of retinoblastoma was described by Morgan ${ }^{29}$ and is said to occur in up to $2 \%$ of cases. ${ }^{30}$

Taktitos also documented the occurrence of most metastatic disease within two years of enucleation. At the time of his survey, chemotheraphy was not being widely used. During the 1950s Hyman and Reese ${ }^{31}$ had treated patients with a nitrogen mustard and its analogue (triethylene melamine) plus radiotherapy in patients with retinoblastoma. Various agents, including cyclophosphamide, vincristine, adriamycin and 5-fluoracil ${ }^{32}$ have since been used. Our indications for chemotherapy in the absence of overt distant spread, are patients with involvement of the cut end of optic nerve, those with extensive choroidal invasion associated with post laminar spread and in the salvage of only eyes which have failed to respond to radiotherapy. The use of cyclophosphamide, an alkylating agent, is avoided in cases of genetic retinoblastoma because of the potential risk of inducing second tumours.

\section{Genetics and retinoblastoma}

Although most cases of retinoblastoma arise sporadically, $20-40 \% 6$ will prove to be hereditary. The mutation rate for the disease, which is inherited as an autosomal dominant, with variable penetrance, is one in 30,000 . The inheritable nature of this disease was not recognised for many years, and was hotly disputed by Parsons as late as $1905 .^{5}$ The heavy mortality, possibly augmented by the social stigma of blindness, militated against discovery of the dominance of this genetic defect. Unfortunately, the first undisputed case was said to have been published in the Brazilian literature (in 1886), ${ }^{5}$ which led to its being overlooked. Ridley in 1904 documented direct and collateral inheritance, supporting von Graefe's hypothesis of 1868. As the 20th century has progressed, documentation and pedigree analysis ${ }^{23}$ has enabled a clearer picture to emerge and Knudson's two-hit hypothesis of $1971^{34}$ went a long way to explaining many of the apparent inconsistancies of inheritable factors.

Lele and Stallard in $1963^{35}$ reported a patient with a deletion of a $\mathrm{D}$ group chromosome. Subsequently the deletion was localised to band 14 of chromosome $13,{ }^{36}$ and ' $13 \mathrm{q}$ minus' syndrome has been asserted to be almost constantly associated with retinoblastoma. ${ }^{37}$ However it occurs in less than $5 \%$ of patients. Other deletions on chromosome 13 , avoiding this locus, are not associated with retinoblastoma. The Esterase D (ESD) gene also lies near the 'retinoblastoma' $(\mathrm{Rb})$ locus and patients with the 13q 14 deletion have fibroblasts and erythrocytes with low levels of ESD enzyme activity. Genetic counselling and prenatal diagnosis, now available on chorionic villus samples taken at eight-10 weeks gestation ${ }^{38}$ using esterase D polymorphisms, are now possible and more recently DNA probes have been prepared and also used in detection. This prenatal diagnosis in known familial disease, in patients heterozygous for ESD, can obviate the necessity of fetal blood sampling at 18 weeks gestation and possible termination as late as 21 weeks. This technique at present is limited to the $17 \%$ of the population who are heterozygous for ESD protein polymorphism and have more than one affected member of the family.

Knudson $^{39}$ in 1976 postulated that absent regions or abnormalities (deletion) of the long arm of chromosome 13 were the genetic basis of the disease. When karyotyping was performed, in some cases of inherited retinoblastoma, the abnormality was confined to the tumour celis alone and in some patients who were constitutionally heterozygous at the esterase D locus, the tumour cells contained only a single enzyme allele variant, whereas all other cells expressed both iso-enzymes. This finding suggested that it is loss of one allele, presumably the normal $\mathrm{Rb}$ gene, from cells in the somatic stage that is responsible for tumorigenesis and has led to some new postulates. ${ }^{40}$

In most cases of retinoblastoma there is no 
discernible morphological abnormality in the chromosomes, at the light or electron microscopic level at current levels of resolution but within the last five years DNA probes have been developed which recognise restriction fragment length polymorphisms. ${ }^{41}$ (RFLP) RFLP probes recognised by chromosome 13 can help to differentiate between differently constructed chromosome 13 homologues at the molecular level. The studies have shown that although the karyotype of tumour cells is ostensibly normal, there has been complete loss ${ }^{43}$ of or deletion of one (normally functioning) chromosome 13 within these cells, which then are then rendered homozygous for the defective function at the RB locus. If the loss of an allele was a random effect, then maternal and paternal alleles should be lost with equal frequency. Studies are currently underway to assess this frequency in retinoblastoma. In Wilm's tumour, (nephroblastoma), ${ }^{41}$ another embryonic tumour of childhood where there are specific intra-tumour deletions of and replacement of chromosome 11, recent research has shown that, in this tumour, which is similar in many ways to retinoblastoma, loss of the alleles is not random and that in most cases, the maternal allele is lost. Subsequently the 'first-hit' occurs in the paternal allele, which is then selectively retained and duplicated. It is thought that maternal genes influence embryonal development, ${ }^{44}$ whilst paternal genes influence extra-embryonic tissues such as placenta, (support for this concept comes with the exclusively male karyotyping of hydatiform mole, where loss of the maternal allele and unopposed paternal allelic domination leads to a non-development of an embryo and unrestricted growth of trophoblast. In normal cells the transforming (tumorigenic) gene alleles are kept suppressed by the two regulatory genes, on maternal and paternal, alleles. If only one of the regulatory gene alleles remains, after the other is made inactive or lost (by somatic mutation or inheritance) suppression of transformation genes still occurs, but if the second regulatory gene is lost then transforming gene alleles are released from their suppressed state and expressed. The process of methylation decreases their expressivity. ${ }^{41}$ In the case of nephroblastoma, if the paternal gene allele is inactivated there is methylation and low expressivity, whereas if the maternal gene is made inactive there is no methylation and high expressivity of the tumour gene. If the second hit involves complete loss of the affected chromosome and retention of the other this would explain the selective retention of paternal chrumosome 11 in most sporadic Wilm's tumours as well as inherited cases. The inheritance of a maternal defective gene may occur if there is only a localised mutation of the locus, rather than complete loss of paternal chromosome 11. A second postulate suggests that similarly, in maternal inheritance there may be a 'leaky' transforming gene on maternal chromosome 11, and the paternal gene is lost in the second mutation. The expression may be late and of low intensity and it is interesting to speculate whether this is the basis of retinomalesions or spontaneously regressed tumours, ${ }^{45}$ in the parents of children who express the gene more fully with retinoblastoma.

No firm indications as to which allele is lost in retinoblastoma are available yet but normal RB locus DNA on chromosome 13 has been isolated, sequenced and cloned and resynthesised to produce RB mRNA-RNA probes. ${ }^{46}$ No normal $\mathrm{RB}$ locus protein has been demonstrated in five tumours examined by Lee et al. ${ }^{46}$ Anti $\mathrm{RB}$ antibodies have been prepared which will precipitate a phosphoprotein which binds to DNA. ${ }^{47}$ This is thought to be a suppressor protein which would normally regulate the target (transforming) genes. This has led to the naming of the RB protein as an antioncogene. ${ }^{41}$ The RB gene is also lost or inactive in osteosarcomas developing as second tumours in patients with retinoblastoma, and moreover appears to be absent in those patients with osteosarcoma ${ }^{48}$ but without a retinoblastoma. Knudson's theory was interpreted as provoking neoplasia by mutagenic factors, however it may be failure to suppress genes rather than acquisition of new promotors that is more important. Another recent piece of evidence suggests that the failure of growth inhibition (a response to transforming growth factor beta 1$)^{49}$ is abolished at the receptor or post receptor level in retinoblastomas due to a RB gene product.

\section{Forty years on:-}

Dunphy in his 1963 Jackson Memorial Lecture ${ }^{13}$ described four ages of retinoblastoma, best summarised as prehistologic, histologic, clinicopathological and therapeutic and recently 
Albert heralded a new fifth age of molecular biology and genetics. ${ }^{5}$ Forty years of research has yielded a vast amount of information. Conventional microscopy, often scorned as 19th century, has added to the sum of knowledge in this period, as has electron microscopy, immunology, genetics, establishment of tumour registries, ${ }^{33}$ molecular biology, improved prenatal diagnostic techniques, biochemistry and an increasingly wide range of surgical, chemotherapeutic and radiotherapeutic techniques. ${ }^{50,51}$ Communication between groups of workers and collaboration in obtaining material for research has increased each year. The last $8 \%$ of patients remains a challenge but $100 \%$ survival, rather than $100 \%$ mortality, appears to be almost tangible and the fifth age is upon us.

The authors wish to thank Mrs Pat Goodwin and Dr John Cowell for their help in producing this paper.

\section{References}

${ }^{1}$ Stallard HB. Retinoblastoma treated by radon seeds and radioactive discs. Ann Roy Coll Surg Eng 1955; 16: 349-66.

${ }^{2}$ Stallard HB. The conservative treatment of retinoblastoma. Doyne Memorial Lecture 1962. Trans Ophthalmol Soc UK 1962; 82: 473-535.

${ }^{3}$ Innes G. The application of physics in the treatment of eye neoplasms. Proceedings of Symposia on ocular and adnexal tumours, St. Louis, C.V. Mosby: 1962.

${ }^{4}$ Ellsworth RM. Retinoblastoma: an overview. In retinoblastoma. ed. Blodi FC. Contemporary issues in ophthalmology 2. Churchill Livingston New York, 1985: 1-10.

${ }^{5}$ Albert DM. Historic review of retinoblastoma. Ophthalmology 1987; 94: 654-62.

${ }^{6}$ Cowell JK, Hungerford J, Jay M, Rutland P. Retinoblastoma - clinical and genetic aspects: a review. J Roy Soc Med 1988; 81: 220-3.

${ }^{7}$ Bader JL, Miller RW, Meadows AT, Zimmerman LE, Champion AA, Voute PA. Trilateral retinoblastoma. Lancet 1980; 2: 582-3.

${ }^{8}$ Dudgeon $\mathbf{J}$ and Lee WR. The trilateral retinoblastoma syndrome. Trans Ophthalmol Soc UK 1983; 103: 523-9.

${ }^{9}$ Zimmerman LE, Burns RP, Wankum G, Tully R, Esterly JA. Trilateral retinoblastoma: ectopic intracranial retinoblastoma associated with bilateral retinoblastoma. J Paediat Ophthalmol Strabis 1982; 19: 320-5.

${ }^{10}$ Brownstein S, Chadarevian J-P, Little JM, Trilateral retinoblastoma: report of two cases. Arch Ophthalmol 1984; 102: 257-62.
${ }^{11}$ Kingston JE, Plowman PN, Hungerford JL. Ectopic intracranial retinoblastoma in childhood. Br J Ophthalmol 1985; 69: 742-8.

${ }^{12}$ Wardrop J. Observations on the fungus haematodes or soft cancer. Edinburgh George Ramsey and Co, 1809.

${ }^{13}$ Dunphy EB. The story of retinoblastoma: The Jackson Lecture 1963. Am J Ophthalmol 1964; 58: $539-52$.

${ }^{14}$ Zimmerman LE. Retinoblastoma and retinocytoma. In Spencer WH Ophthalmic Pathology: an atlas and textbook. Vol 2, Philadelphia: WB Saunders 1984: 1292-351.

${ }^{15}$ Parkhill EM, Benedict WB. Gliomas of the retina, a histopathological study. Am J Ophthalmol 1941; 24: 1354-73.

${ }^{16}$ Kyritsis AP, Tsokos M, Triche TJ, Chader GJ. Retinoblastoma - origin from a primitive neuroectodermal cell? Nature 1984; 307: 471-3.

${ }^{17}$ Tso MOM, Fine BS, Zimmerman LE, Vogel MH. Photoreceptor elements in retinoblastoma. A preliminary report. Arch Ophthalmol 1969; 82: 57-9.

${ }^{18}$ Tso MOM, Zimmerman LE, Fine BS, Ellsworth RM. A cause of radioresistance in retinoblastoma: photoreceptor differentiation. Trans Am Acad Ophthalmol Otolaryngol 1970; 74: 959-69.

${ }^{19}$ Margo C, Hidayat A, Kopelman J, Zimmerman LE. Retinocytoma: a benign variant of retinoblastoma. Arch Ophthalmol 1983; 101: 1519-31.

${ }^{20}$ Abramson DH. Retinoma, retinocytoma and the retinoblastoma gene. Arch Ophthalmol 1983; 187: $1517-8$.

${ }^{21}$ Terenghi G, Polak JM, Ballesta J, Cocchia D, Michetti F, Dahl D, Marangos PJ, Garner A. Immunocytochemistry of neuronal and glial markers in retinoblastoma. Virchows Archiv Pathol Anat 1984; 404: 61-73.

${ }^{22}$ Rodriguez MM, Wilson ME, Wiggert B, Krishna G, Chader GJ. Retinoblastoma. A clinical immunohistochemical and electron microscopic report. Ophthalmology 1986; 93: 1010-15.

${ }^{23}$ Craft JL, Sang DN, Dryja TP, Brockhurst RJ, Robinson NL, Albert DM. Glial cell component in retinoblastoma. Exp Eye Res 1985; 40: 647-59.

${ }^{24}$ Messmer EP, Font RL, Kirkpatrick JB, Höpping W. Immunohistochemical demonstration of neuronal and astrocytic differentiation in retinoblastoma. Ophthalmology 1985; 92: 167-73.

${ }^{25}$ Sang DN, Albert DM. Recent advances in the study of retinoblastoma. In Peyman GA, Apple DJ, Sanders DR eds. Intraocular Tumours. New York: Appleton-Century-Crofts 1977; 285-329.

${ }^{26}$ Olver JM, McCartney ACE, Kingston J, Hungerford J. Histological indicators of the 
prognosis for survival following enucleation for retinoblastoma. Proc 2nd International Intraocular Tumour Meeting Nyon Nov 1987; Springer Verlag, (in press).

${ }^{27}$ Taktitos A. Investigation of retinoblastoma with special reference to histology and prognosis. $\mathrm{Br} J$ Ophthalmol 1966; 50: 225-34.

${ }^{28}$ Garner A, Kanski J, Kinnear F. Retinoblastoma: report of a case with minimal retinal component but massive anterior segment spread. $\mathrm{Br} J$ Ophthalmol 1987; 71: 858-63.

${ }^{29}$ Morgan G. Diffuse infiltrating retinoblastoma. $\mathrm{Br} \mathrm{J}$ Ophthalmol 1971; 55: 600-6.

${ }^{30}$ Nicholson DH. Retinoblastoma. Current concepts in Ocular Pathology Update. New York Masson 1980; 235-44.

${ }^{31}$ Hyman GA, Reese AB. Combination therapy of retinoblastoma with triethylene melamine and radiotherapy. $J$ Am Med Assoc 1956; 162: 1368-73.

${ }^{32}$ Shields JA, Ausberger JJ. Current approaches to the diagnosis and management of retinoblastoma. Surv Ophthalmol 1981; 25: 347-72.

${ }^{33}$ Jay M, Cowell JK, Hungerford J. Register of retinoblastoma: preliminary results. Eye 1988; 2: 102-5.

${ }^{34}$ Knudson AG. Mutation and cancer: statistical study of retinoblastoma. Proc Natl Acad Sci USA 1971; 68: 820-3.

${ }^{35}$ Lele KP, Penrose LS, Stallard HB. Chromosome deletion in a case of retinoblastoma. Ann Hum Genet 1963; 27: 171-4.

${ }^{36}$ Yunis JJ, Ramsay N. Retinoblastoma and sub-band deletion of chromosome 13. Am J Dis Child 1978; 132: $161-3$.

${ }^{37}$ Liberfarb RM, Bustos T, Miller WA, Sang D. Incidence and significance of a deletion of chromosome band $13 \mathrm{q} 14$ in patients with retinoblastoma and in their families. Ophthalmology 1984; 91: 1695-9.

${ }^{38}$ Mitchell C, Nicolaides K, Kingston J, Hungerford J, Jay M, Cowell J. Prenatal exclusion of hereditary retinoblastoma. Lancet 1988; i: 826 (\& 954).
${ }^{39}$ Knudson AG, Meadows AT, Nichols WWHR. Chromosomal deletion and retinoblastoma. $N$ Engl J Med 1976; 295: 1120-23.

${ }^{40}$ Gallie BL, Phillips RA. Retinoblastoma: a model of oncogenesis. Ophthalmology 1984; 91: 666-72.

${ }^{41}$ Wilkins RJ. Genomic imprinting and carcinogenesis. Lancet 1988; i: 329-31.

${ }^{42}$ Goudie RB. What are antioncogenes? Editorial. $J$ Pathol 1988; 154: 297-300.

${ }^{43}$ Fung YKT, Murphree AL, T'Ang A, Qian J, Hinrichs SH, Benedict WF. Structural evidence for the authenticity of the human retinoblastoma gene. Science 1987; 236: 1657-61.

${ }^{44}$ Monk M. Genomic imprinting. Memories of mother and father. Nature 1987; 328: 203-4.

${ }^{45}$ Boniuk $\mathrm{M}$, and Zimmerman LE. Spontaneous regression of retinoblastoma. Int Ophthalmol Clin 1962; 2: 525-42.

${ }^{46}$ Lee WH, Bookstein R, Hong F, Young L-J, Shew J-Y, Lee EY-H. Human retinoblastoma susceptibility gene: cloning, identification and sequence. Science 1987; 235: 1394-9.

${ }^{47}$ Lee WH, Shew J-Y, Hong FD, Sery TW, Donoso LA, Young L-J, Bookstein R, Lee EY-H. The retinoblastoma susceptibility gene encodes a nuclear phosphoprotein associated with DNA binding activity. Nature 1987; 329: 642-5.

${ }^{48}$ Friend SH, Bernards R, Rogeli S, Weinberg RA, Rapaport JM, Albert DM, Dryja TP. A human DNA segment with properties of the gene that predisposes to retinoblastoma and osteosarcoma. Nature 1986; 323: 643-6.

${ }^{49}$ Kimchi A, Wang X-F, Weinberg RA, Cheifetz S, Massague J. Absence of TGF-B receptors and growth inhibiting responses in retinoblastoma cells. Science 1988; 240: 196-9.

${ }^{50}$ Howarth C, Meyer D, Hustu HO, Johnson W, Shanks E, Pratt C. Stage related combined modality treatment of retinoblastoma: results of a prospective study. Cancer 1980; 45: 851-8.

${ }^{51}$ Harnett An, Hungerford JL, Lambert GD, Hirst A, Darlinson R, Hart BL, Trodd TL, Plowman PN. Improved external beam radiotherapy for the treatment of retinoblastoma. Br J Radiol 1987; 60: $753-60$. 